IJMMS 31:11 (2002) 701-702

PII. S0161171202202197

http://ijmms.hindawi.com

(c) Hindawi Publishing Corp.

\title{
A NOTE ON A PAPER BY BRENNER
}

\section{PAVLOS TZERMIAS}

Received 4 February 2002

We note that a result of Brenner (1962) follows from a theorem of Lerch (1896) which also extends it.

2000 Mathematics Subject Classification: 11A15, 05A05.

Let $m$ and $n$ be relatively prime integers with $n \geq 2$. Let $\sim$ be the equivalence relation on the set $S=(\mathbb{Z} / n \mathbb{Z}) \backslash\{0\}$ given by $t_{1} \sim t_{2}$ if and only if there exists an integer $k$ such that $m^{k} t_{1}=t_{2}$. Denote by $N$ the number of equivalence classes. Brenner proved the following result [1].

THEOREM 1. If $n$ is odd, then $(-1)^{N}$ equals the Jacobi symbol $(m / n)$.

The purpose of this note is to point out that the above result is a consequence of a theorem of Lerch [3] dating back to 1896, which, moreover, extends Theorem 1 to the case of even $n$.

THEOREM 2 (Lerch). For relatively prime integers $m$ and $n$, with $n \geq 2$, the sign of the permutation $\pi$ induced by multiplication by $m$ on $(\mathbb{Z} / n \mathbb{Z}) \backslash\{0\}$ equals

(a) the Jacobi symbol $(m / n)$ if $n$ is odd;

(b) 1 if $n$ is even and not divisible by 4 ;

(c) $(-1)^{(m-1) / 2}$ if $n$ is divisible by 4 .

Observe that $N$ is the number of cycles $\tau_{1}, \ldots, \tau_{N}$ in the decomposition of $\pi$ into a product of disjoint cycles (1-cycles need to be included). Now if $l_{i}$ is the length of $\tau_{i}$, then the sign of $\tau_{i}$ equals $(-1)^{l_{i}-1}$, so, if $n$ is odd, the sign of $\pi$ equals

$$
(-1)^{\sum_{i=1}^{N}\left(l_{i}-1\right)}=(-1)^{n-1-N}=(-1)^{N} .
$$

Thus Theorem 1 follows from Theorem 2, as does the following extension.

COROLlary 3. For $n$ even $(-1)^{N}$ equals -1 , if $n \equiv 2(\bmod 4)$, and $(-1)^{(m+1) / 2}$, if $n \equiv 0(\bmod 4)$.

Lerch's theorem, which generalizes a result of Zolotareff [4] on the Legendre symbol, considerably simplifies the theory of quadratic residues (see, e.g., [2]) and deserves to be more widely known.

\section{REFERENCES}

[1] J. L. Brenner, A new property of the Jacobi symbol, Duke Math. J. 29 (1962), 29-31.

[2] F. Hirzebruch and D. Zagier, The Atiyah-Singer Theorem and Elementary Number Theory, Mathematics Lecture Series, no. 3, Publish or Perish, Massachusetts, 1974. 
[3] M. Lerch, Sur un théorème de Zolotarev, Bull. Intern. de l'Acad. François Joseph 3 (1896), 34-37 (French).

[4] G. Zolotareff, Nouvelle demonstration de la loi de réciprocité de Legendre, Nouvelles Annales de Math. 11 (1872), no. 2, 354-362 (French).

Pavlos Tzermias: Department of Mathematics, University of Tennessee, Knoxville, TN 37996, USA

E-mail address: tzermias@math.utk.edu 


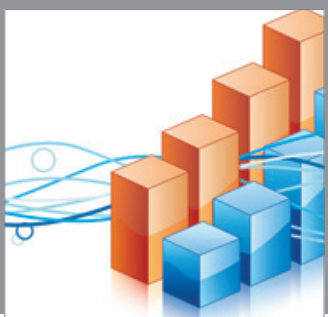

Advances in

Operations Research

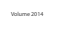

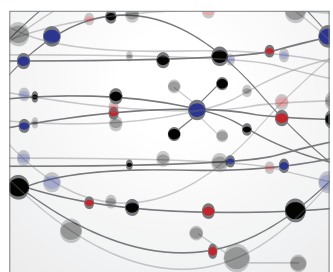

\section{The Scientific} World Journal
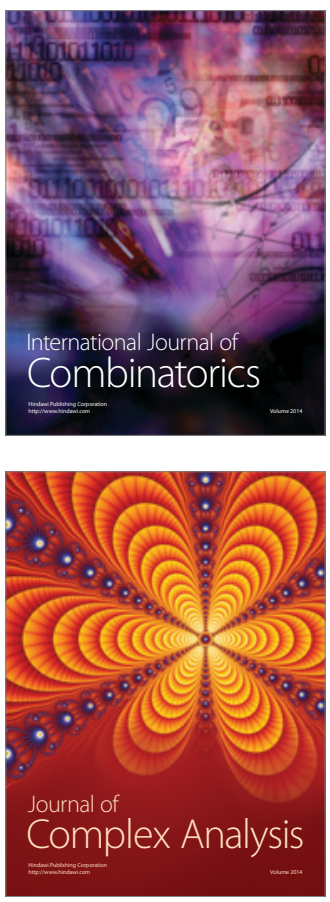

International Journal of

Mathematics and

Mathematical

Sciences
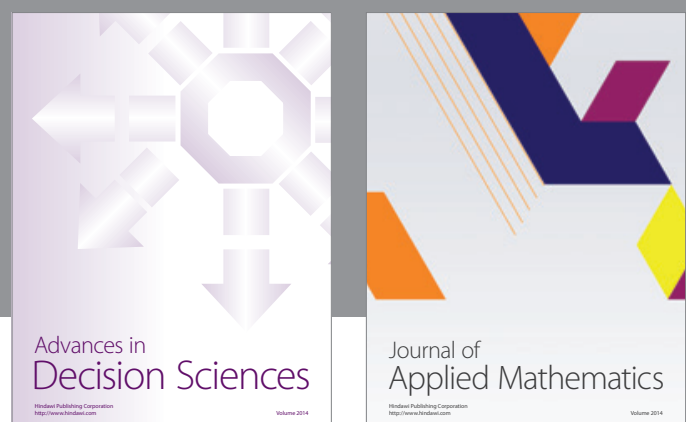

Journal of

Applied Mathematics
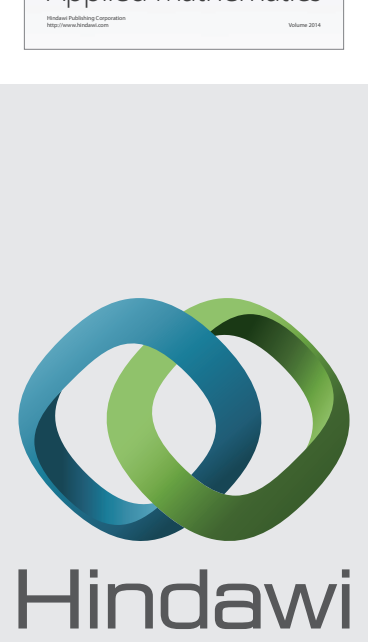

Submit your manuscripts at http://www.hindawi.com
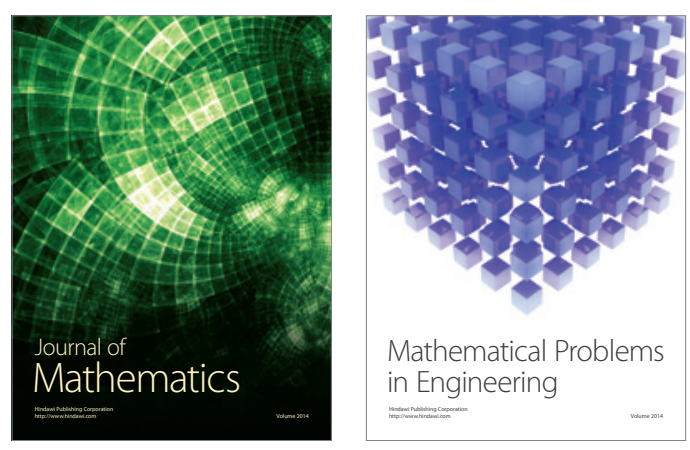

Mathematical Problems in Engineering
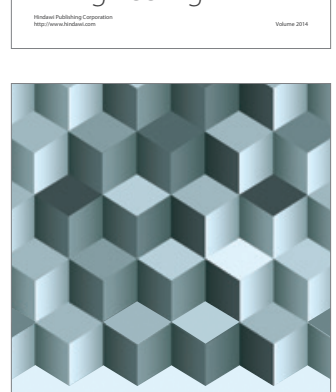

Journal of

Function Spaces
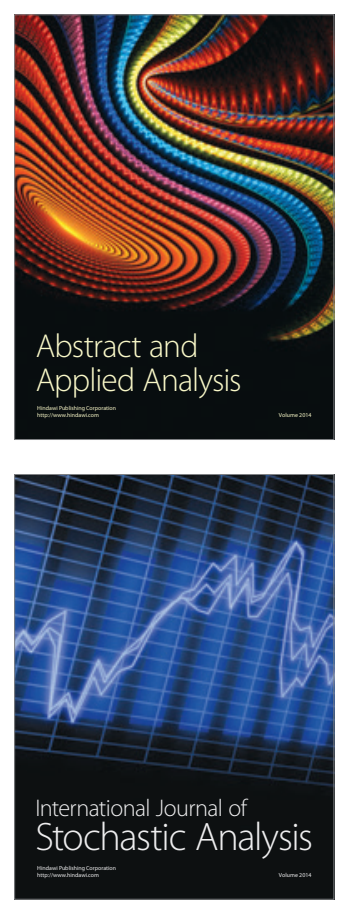

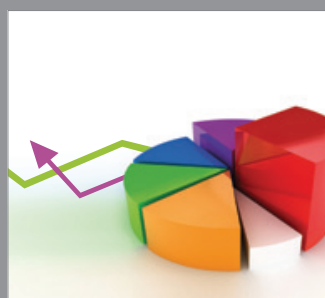

ournal of

Probability and Statistics

Promensencen
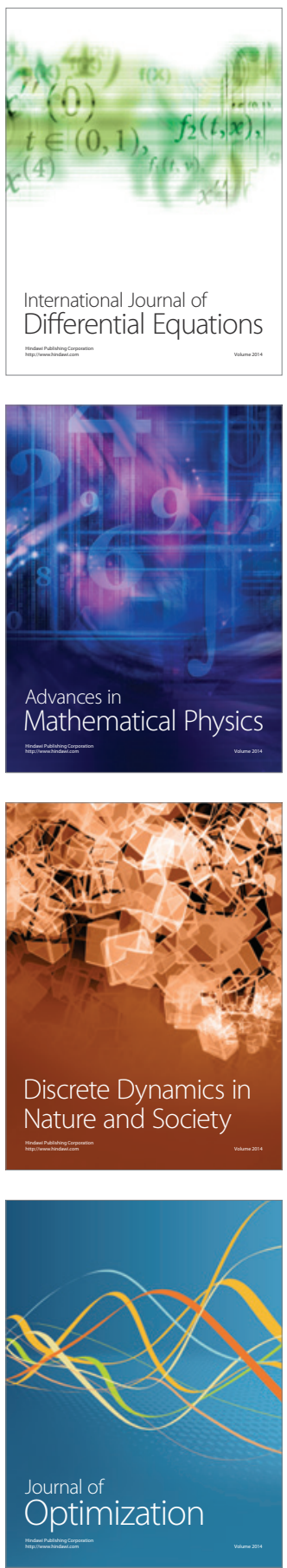